\title{
Characterisation of $\delta$-Conotoxin TxVIA as a Mammalian T-Type Calcium Channel Modulator
}

\author{
Dan Wang ${ }^{1}{ }^{\mathbb{D}}$, S.W.A. Himaya ${ }^{1}$, Jean Giacomotto ${ }^{2,3}{ }^{\circledR}$, Md. Mahadhi Hasan ${ }^{1}$, \\ Fernanda C. Cardoso ${ }^{1}\left(\mathbb{D}\right.$, Lotten Ragnarsson ${ }^{1}$ and Richard J. Lewis ${ }^{1, * \mathbb{D}}$ \\ 1 Institute for Molecular Bioscience, The University of Queensland, Brisbane, QLD 4072, Australia; \\ dan.wang@imb.uq.edu.au (D.W.); h.siddhihalu@imb.uq.edu.au (S.W.A.H.); \\ mahadhi.hasan@imb.uq.edu.au (M.M.H.); f.caldascardoso@imb.uq.edu.au (F.C.C.); \\ l.ragnarsson@imb.uq.edu.au (L.R.) \\ 2 Queensland Brain Institute, The University of Queensland, Brisbane, QLD 4072, Australia; \\ j.giacomotto@uq.edu.au \\ 3 Queensland Centre for Mental Health Research, West Moreton Hospital and Health Service and University \\ of Queensland, Brisbane, QLD 4072, Australia \\ * Correspondence: r.lewis@imb.uq.edu.au; Tel.: +617-3346-2984
}

Received: 12 May 2020; Accepted: 25 June 2020; Published: 30 June 2020

\begin{abstract}
The 27-amino acid (aa)-long $\delta$-conotoxin TxVIA, originally isolated from the mollusc-hunting cone snail Conus textile, slows voltage-gated sodium $\left(\mathrm{Na}_{\mathrm{V}}\right)$ channel inactivation in molluscan neurons, but its mammalian ion channel targets remain undetermined. In this study, we confirmed that TxVIA was inactive on mammalian $\mathrm{Na}_{\mathrm{V}} 1.2$ and $\mathrm{Na}_{\mathrm{V}} 1.7$ even at high concentrations $(10 \mu \mathrm{M})$. Given the fact that invertebrate $\mathrm{Na}_{V}$ channel and T-type calcium channels $\left(\mathrm{Ca}_{\mathrm{V}} 3 . \mathrm{x}\right)$ are evolutionarily related, we examined the possibility that TxVIA may act on $\mathrm{Ca}_{\mathrm{V}} 3 . x$. Electrophysiological characterisation of the native TxVIA on Cav3.1, 3.2 and 3.3 revealed that TxVIA preferentially inhibits Cav3.2 current $\left(\mathrm{IC}_{50}=0.24 \mu \mathrm{M}\right)$ and enhances Cav3.1 current at higher concentrations. In fish bioassays TxVIA showed little effect on zebrafish behaviours when injected intramuscular at $250 \mathrm{ng} / 100 \mathrm{mg}$ fish. The binding sites for TxVIA at Nav1.7 and $\mathrm{Ca}_{\mathrm{V}} 3.1$ revealed that their channel binding sites contained a common epitope.
\end{abstract}

Keywords: TxVIA; mammalian Nav channel; selective inhibitor; T-type Cav3.2

\section{Introduction}

The $\delta$-conotoxin TxVIA (King Kong peptide), a 27-amino acid (aa)-long peptide with six cysteine residues, was originally isolated from the mollusc-hunting cone snail species Conus textile [1]. The unique name of TxVIA, "King Kong peptide", stems from the dominant posture lobsters adopt following injection of the toxin, although it has also been observed to produce convulsive-like activity in snails [1]. TxVIA also produced a paralytic effect in molluscs (Patella) but not in fish (Cambusia), insects (Sarcophaga) or crustaceans (Porcellio) [2]. Although no mammalian activity has been reported, TxVIA was shown to potently slow $\mathrm{Na}_{\mathrm{V}}$ channel inactivation in molluscs [3]. Previous binding and electrophysiological studies suggest TxVIA binds to both mollusc and rat brain Navs at sites adjacent to the binding sites of conotoxin CsTx and coral toxin GPT [4-6]. However, TxVIA binding to mammalian Nav channels is non-functional [4]. The disparate sequence alignment of the Aplysia $\mathrm{Na}_{V}$ channel with hNav1.7 (44\% similarity overall, with especially poor overlap across the extracellular regions) supports the distinct modes of action at these distantly related sodium channels.

T-type calcium channels $\left(\mathrm{Ca}_{\mathrm{V}} 3 . \mathrm{x}\right)$ have been identified with two ion-selectivity filters [7], which allow permeability to $\mathrm{Na}^{+}$ions in the absence of $\mathrm{Ca}^{2+}$ ions, with genomic studies on the 
jellyfish $\mathrm{Na}_{\mathrm{V}}$ channel, revealing an ancestral resemblance to $\mathrm{Ca}_{\mathrm{V}} 3 . x$ [8]. $\mathrm{Ca}_{\mathrm{V}} 3 . x$ provides a privileged gate for calcium influx that initiates many physiological events including secretion, neurotransmission and cell proliferation $[9,10]$, implicating it in many pathophysiological disorders and diseases, including absence epilepsy, Parkinson's disease (PD), hypertension, cardiovascular diseases, cancers and pain [11]. The evolutionary relationship between the invertebrate $\mathrm{Na}_{\mathrm{V}}$ channel with $\mathrm{Ca}_{\mathrm{V}} 3 . \mathrm{x}$ raised the possibility that TxVIA may modulate Cav3.x.

In this work, we identified the spatial distribution of TxVIA in the C. textile venom duct, isolated and characterised native TxVIA at human $\mathrm{Ca}_{V} 3 . x$ using Fluorescent Imaging Plate Reader (FLIPR) and electrophysiological (QPatch) assays, confirmed the lack of activity of TxVIA on human Nav channels endogenously expressed in SH-SY5Y cells [12] and mouse $\mathrm{Na}_{V} 1.7$, and used zebrafish [13,14] to analyse behavioural effects using an automated tracking device (i.e. Zebrabox). Finally, we compared the binding sites for TxVIA predicted from molecular docking studies using homology models of $\mathrm{Na}_{\mathrm{V}} 1.7$ and $\mathrm{Ca}_{\mathrm{V}} 3.1$.

\section{Results}

\subsection{Distribution, Isolation and Identification of Native TxVIA}

C. textile venom ducts of thirteen specimens (TEX-1-13) were dissected into distal (D), distal central (DC), proximal central (PC) and proximal (P) sections, and the extracted venom from each section was analysed by liquid chromatography/mass spectrometry (LC/MS). TxVIA expression across the thirteen specimens (Figure 1a) was localised to the central portions of the C. textile venom duct. Guided by TxVIA distribution, the distal central venom of TEX-4 was selected for fractionation (Figure 1b). Native TxVIA was isolated and its amino acid sequence WCKQSGEMCNLLDQNCCDGYCIVLVCT confirmed by tandem mass spectrometry (MS/MS) analysis.

a

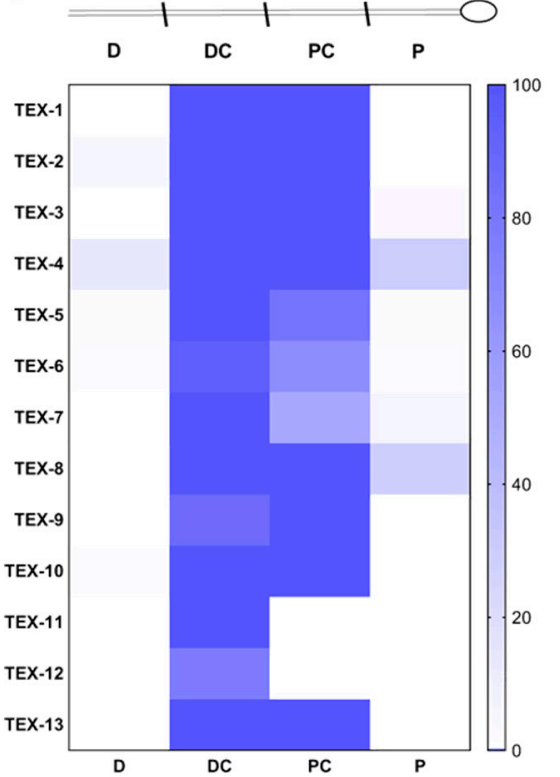

b



Figure 1. (a) TxVIA distribution across the four venom duct sections (distal (D), distal central (DC), proximal central (PC), proximal (P)) of 13 Conus textile specimens. (b) Partial chromatogram of TEX-4 $\mathrm{DC}$ section fractionation. The $x$-axis represents the retention time, the $y$-axis represents UV absorption at $214 \mathrm{~nm}$, and the red arrow indicates TxVIA eluting at $62.5 \mathrm{~min}$ (mass data obtained by MALDI-TOF MS).

\subsection{Evaluation of Mammalian $\mathrm{Na}_{V}$ Channel Activitiy of TxVIA using FLIPR Cell-Based Assays}

TxVIA $(5 \mu \mathrm{M})$ was tested in SH-SY5Y cells using a FLIPR assay to measure endogenously expressed $\mathrm{Na}_{\mathrm{V}} 1.2$ and $\mathrm{Na}_{\mathrm{V}} 1.7$ [12]. Although $0.5 \mu \mathrm{M}$ TxVIA has previously been shown to slow inactivation of 
molluscan $\mathrm{Na}_{\mathrm{V}}$ current [3], $5 \mu \mathrm{M}$ TxVIA did not produce any detectable effect on human $\mathrm{Na}_{\mathrm{V}}$ responses in SH-SY5Y cells $(n=3, p=0.37)$ (Figure $2 \mathrm{a})$. TxVIA $(10 \mu \mathrm{M})$ also failed to significantly modify calcium influx in HEK cells transiently expressing mouse $\mathrm{Na}_{\mathrm{V}} 1.7(n=2, p=0.29)$ (Figure 2b).

a

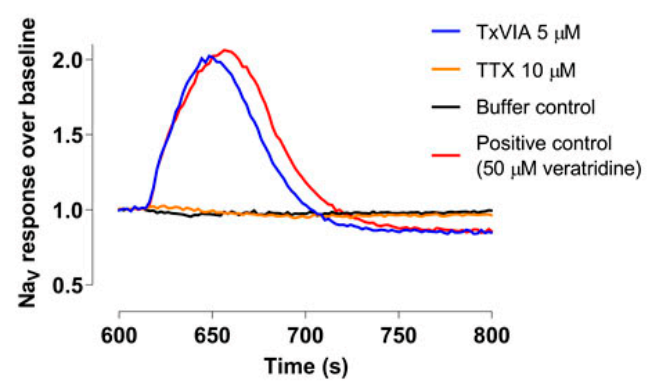

b

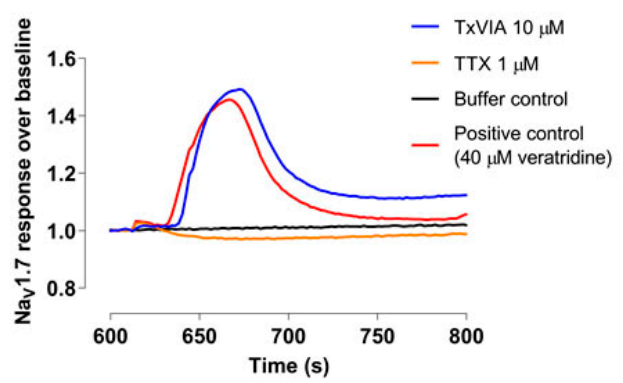

Figure 2. Characterisation of TxVIA in sodium channels. (a) Representative fluorescent traces of the $\mathrm{hNa}_{\mathrm{V}}$ responses with and without the addition of $5 \mu \mathrm{M}$ TxVIA. (b) Representative fluorescent traces of the mouse $\mathrm{Na}_{V} 1.7$ responses with and without the addition of $10 \mu \mathrm{M}$ TxVIA.

a $\left(\mathrm{Ca}_{\mathrm{v}} 3.2\right)$

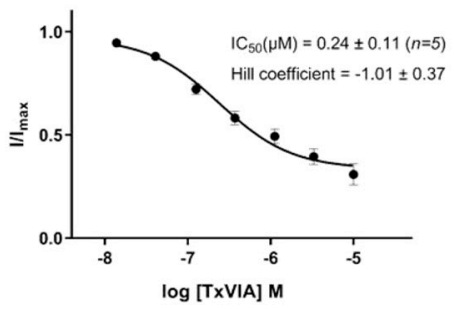

d $\left(\mathrm{Ca}_{\mathrm{v}} 3.1\right)$

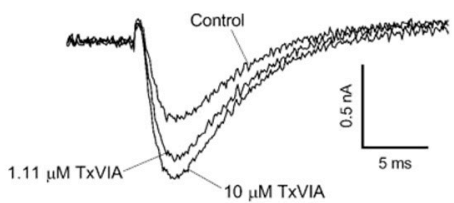

b $\left(\mathrm{Ca}_{\mathrm{v}} 3.2\right)$

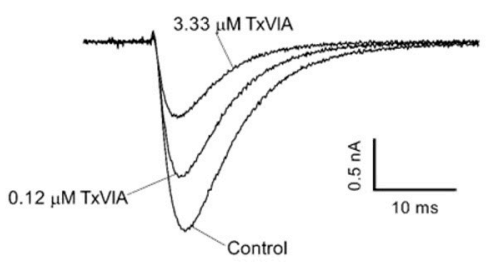

e $\left(\mathrm{Ca}_{\mathrm{v}} 3.1\right)$

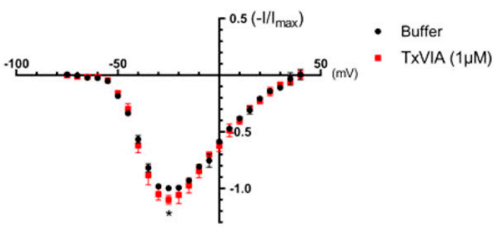

c $\left(\mathrm{Ca}_{\mathrm{v}} \mathrm{3.3}\right)$

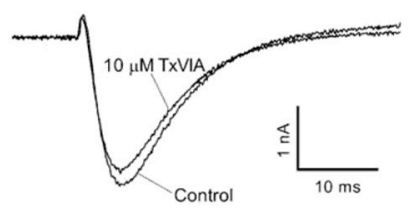

f $\left(\mathrm{Ca}_{\mathrm{v}} 3.2\right)$

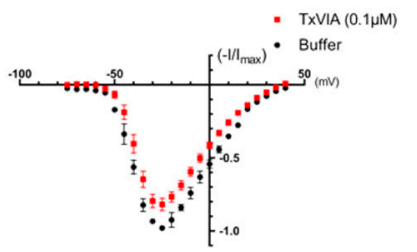

Figure 3. Modulation of $\mathrm{Ca}_{V} 3.1, \mathrm{Ca}_{V} 3.2$ and $\mathrm{Ca}_{V} 3.3$ current by TxVIA. (a) Concentration response curves of TxVIA on recombinant hCa 3.2 channels $(n=5)$ using the QPatch. Data are means \pm SEM. (b) Representative $\mathrm{Ca}_{\mathrm{V}} 3.2 \mathrm{I}_{\mathrm{Ca}}$ during $200 \mathrm{~ms}$ depolarisations to $\mathrm{V}_{\max }(-20 \mathrm{mV})$ from a holding potential of $-90 \mathrm{mV}$ before and after perfusions of $0.12 \mu \mathrm{M}$ and $3.33 \mu \mathrm{M}$ of TxVIA, as indicated. (c) Representative Cav3.3 $\mathrm{I}_{\mathrm{Ca}}$ during $200 \mathrm{~ms}$ depolarisations to $\mathrm{V}_{\max }(-10 \mathrm{mV})$ from a holding potential of $-90 \mathrm{mV}$ before and after perfusions of $10 \mu \mathrm{M}$ of TxVIA, as indicated. (d) Representative Cav3.1 $\mathrm{I}_{\mathrm{Ca}}$ during $200 \mathrm{~ms}$ depolarisations to $\mathrm{V}_{\max }(-20 \mathrm{mV})$ from a holding potential of $-90 \mathrm{mV}$ before and after perfusions of $1.11 \mu \mathrm{M}$ and $10 \mu \mathrm{M}$ of TxVIA, as indicated. (e) Normalised I-V relationships of Ca $3.1(n=5)$ plotted from $-75 \mathrm{mV}$ to $+40 \mathrm{mV}$ before (black) and after (red) the addition of $1 \mu \mathrm{M}$ of TxVIA, $\mathrm{V}_{\max }$ at $-25 \mathrm{mV}(10.0 \% \pm 3.9 \%$ current enhancement, $p=0.04), I_{\max }$ at $0.12 \pm 0.01 \mathrm{nA}$. Data are means $\pm \mathrm{SEM}$. Single-voltage protocol was applied in between to measure the TxVIA effect. (f) Normalised I-V relationships of $\mathrm{Ca}_{\mathrm{V}} 3.2(n=4)$ plotted from $-75 \mathrm{mV}$ to $+40 \mathrm{mV}$ before (black) and after (red) the addition of $0.1 \mu \mathrm{M}$ of TxVIA, $\mathrm{V}_{\max }$ at $-25 \mathrm{mV}, \mathrm{I}_{\max }$ at $0.65 \pm 0.04 \mathrm{nA}$. Data are means \pm SEM. Single-voltage protocol was applied in between to measure the TxVIA effect.

\subsection{Pharmacological Characterisation of TxVIA in $\mathrm{Ca}_{V} 3 \cdot x$}

We examined the effects of native TxVIA on human Cav3.x by whole-cell patch-clamp using the automated electrophysiology platform QPatch 16 X (Figure 3). Whereas TxVIA partially inhibited $\mathrm{Ca}_{\mathrm{V}} 3.2(n=5)$ (Figure 3a,b) at high nanomolar concentrations, it had little effect on Ca⒊3 $(n=6)$ 
(Figure 3c) and promoted the opening of $\mathrm{Ca}_{\mathrm{V}} 3.1(n=5)$ (Figure 3d). Current-voltage $(I-V)$ relationships of $\mathrm{Ca}_{\mathrm{V}} 3.1$ in the presence of $1 \mu \mathrm{M}$ TxVIA revealed that the channel modulation was not accompanied by shifts in the $I-V$ relationship $(n=5, p=0.63)$ (Figure 3e). Similarly, $0.1 \mu \mathrm{M}$ TxVIA did not shift the $I-V$ relationship of Cav3.2 $(n=4, p=0.21)$ (Figure $3 f)$. We also tested native TxVIA in the Cav3.2 FLIPR window current assay [15], where $60 \mu \mathrm{M}$ TxVIA only showed partial $(42 \%)$ inhibition $(n=3)$ (data not shown).

\subsection{TxVIA Docking in Human $\mathrm{Na} a_{V} 1.7$ and $\mathrm{Ca} a_{V} 3 . x$}

Previous binding and electrophysiological studies have suggested that TxVIA binds to a variety of $\mathrm{Na}_{V} s$ despite its lack of functional effects on rat brain $\mathrm{Na}_{V} s$ [4], and human $\mathrm{Na}_{V} 1.2$ and $\mathrm{Na}_{V} 1.7$ responses (present study). The binding site of TxVIA is expected to be extracellular, likely adjacent to but distinct from neurotoxin site 3 [4-6]. Site 3 was initially recognised to be located in the S5-S6 linker of domain I (DI) and IV (DIV) [16], and a later study identified that additional residues in the DIV S3-S4 linker influenced $\alpha$-scorpion and sea anemone toxin binding $[17,18]$. Based on this background, we docked TxVIA to the DIV S3-S4 linker of the cryo-electron microscopy (Cryo-EM) structure of human $\mathrm{Na}_{\mathrm{V}}$ 1.7- $\beta 1-\beta 2$ complex (Protein Data Bank (PDB) code 6J8I) [19]. This docking generated a docking pose where TxVIA fits between the DIV S1-S2 and S3-S4 linkers of Na 1.7 (Figure 4a,b) (Table 1). Importantly, this binding pose identified a strong salt bridge between K3 in TxVIA and E1545 in the DIV S1-S2 linker that is a likely key binding determinant (Figure 4b).
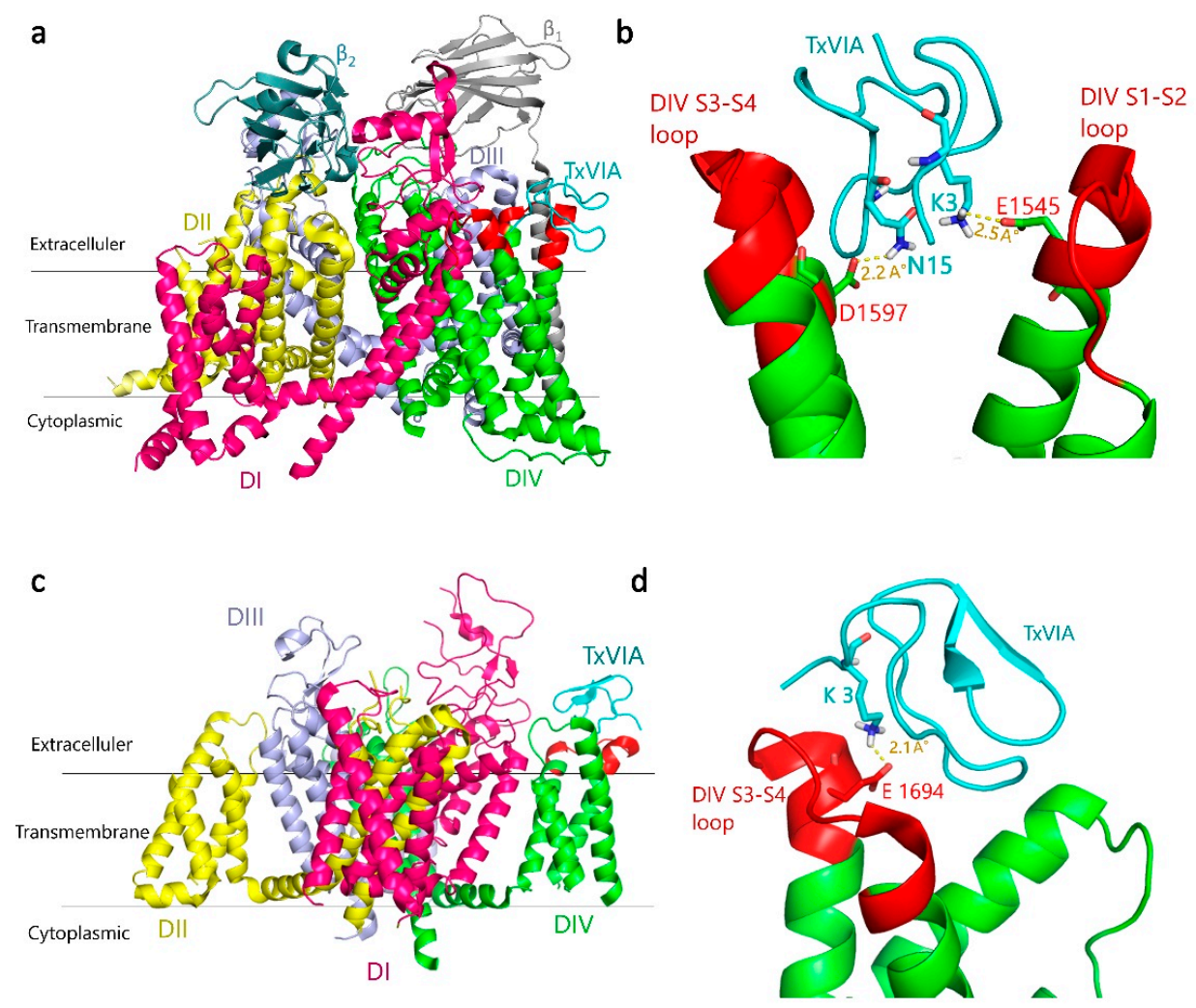

Figure 4. Predicted binding mode of TxVIA (coloured cyan) in human Nav1.7 and Cav3.1. (a) General view of the lowest energy docking pose of TxVIA binding to $\mathrm{hNa}_{\mathrm{V}} 1.7$ DIV S3-S4 and S1-S2 linkers (extracellular loops, coloured red). (b) Local view of TxVIA interactions highlighting that D1597 in $\mathrm{hNa}_{\mathrm{V}}$ 1.7 DIV S3-S4 linker and E1545 in DIV S1-S2 linker make close contact with N15 and K3 of TxVIA, respectively. (c) General view of the lowest energy docking pose of TxVIA binding to hCaV3.1 DIV S3-S4 linker (coloured red). (d) Local view of the close interaction between K3 in TxVIA and E1694 in the hCav3.1 DIV S3-S4 linker. Predicted hydrogen bonds are shown as yellow dashed lines, with distances shown in $\AA$. 
Table 1. TxVIA binding affinity in human $\mathrm{Na}_{V} 1.7$ and $\mathrm{Ca}_{V} 3 . x$.

\begin{tabular}{cc}
\hline Docking Target & Molar Affinity (kcal/mol) \\
\hline $\mathrm{hNa}_{V} 1.7$ DIV S3-S4 & -3.2 \\
$\mathrm{hNa}$ 1.7 DII S3-S4 & 7.2 \\
$\mathrm{hCa} 3.1$ DIV S3-S4 & -4.0 \\
$\mathrm{hCa} 3.2$ DIV S3-S4 & 49.1 \\
$\mathrm{hCa} 3.3$ DIV S3-S4 & 31.8 \\
\hline
\end{tabular}

The 30-aa spider toxin ProTx-II, initially identified as a Na 1.7 selective blocker [20], has also been shown to selectively block the hCav 3.2 current among the three $\mathrm{Ca}_{\mathrm{V}} 3 . \mathrm{x}$ subtypes [21]. As a well-established site 4 (DII S3-S4 linker) toxin [22], the crystal structure of the ProTx-II-DII hNa 1.7 complex [23] has been generated. It has been suggested that TxVIA binds to a different binding site from ProTx-II [4], which was also supported by our docking results with unfavourable binding affinity (Table 1).

We also explored TxVIA binding in hCav3.x. The MolProbity score of Cav3.2 and Cav3.3 homology models generated from the recently reported hCav3.1 Cryo-EM structure [24] were 1.97 and 1.98 respectively, indicating the high quality of the modelled structures. An assessment of the Ramachandran plot showed that only $1.85 \%$ and $1.34 \%$ residues fell in outlier regions for Cav3.2 and Cav3.3 models, respectively, with no outliers found for residues in the DIV S3-S4 linker region.

The selective inhibition of ProTx-I [21] for $\mathrm{Ca}_{\mathrm{V}} 3.1$ current over $\mathrm{Ca}_{\mathrm{V}} 3.2$ has been identified to be partly attributed to the DIV S3-S4 linker in T-type Ca $\mathrm{V}_{\mathrm{V}}$ [25]. Interestingly, our docking results also suggest that TxVIA would bind to the DIV S3-S4 linker of Ca 3.1 (Figure 4c,d) with higher affinity than to $\mathrm{Ca}_{\mathrm{V}} 3.2$ and $\mathrm{Ca}_{\mathrm{V}} 3.3$ (Table 1). However, the possibility that the DIV S3-S4 linker may contribute to the activation of $\mathrm{Ca}_{V} 3.1$ by TxVIA requires further study. Similar to its docking at $\mathrm{Na}_{\mathrm{V}} 1.7$, the best docking pose for TxVIA binding to Cav3.1 shows TxVIA interacting between DIV S1-S2 and S3-S4 linkers of $\mathrm{Ca}_{\mathrm{v}} 3.1$. As shown in Figure $4 \mathrm{~d}$, a strong salt bridge was again identified between $\mathrm{K} 3$ in TxVIA and E1694 in the Cav3.1 DIV S3-S4 linker, although no interactions were identified between TxVIA and the S1-S2 in Cav3.1 DIV.

\subsection{Behavioural Analysis on Zebrafish after Intramuscular Injection of TxVIA}

Although the TxVIA inhibition of Cav3.2 indicated possible pain-relieving activity, its activation of Cav3.1 indicated a possible pain inducing activity, albeit at higher concentrations. We also showed that TxVIA had no effect on the human pain related $\mathrm{Na}_{\mathrm{V}}$ 1.7. Given the potential of TxVIA to play a defensive role, we examined its effect on zebrafish at concentrations up to $250 \mathrm{ng} / 100 \mathrm{mg}$ fish. However, TxVIA could have different pharmacology on zebrafish and mammalian $\mathrm{Ca}_{V} s$ and $\mathrm{Na}_{V} s$ that may influence interpretation of responses in zebrafish.

None of the injected fish showed signs indicative of pain-related behaviours or paralysis after the injection ( $n=3, p=0.37$ ), and no adverse effects were observed in the $24 \mathrm{~h}$ post-injection. Fish swimming tracks were also recorded during the first $15 \mathrm{~min}$ post-injection (see Figure 5). Zebrafish injected with $250 \mathrm{ng} / 100 \mathrm{mg}$ fish of TxVIA showed reduced swimming activity compared to control fish in the first $8 \mathrm{~min}$, however this effect did not reach significance and soon reversed to normal edge swimming. Additionally, the absence of swimming bursts or erratic swimming behaviour after TxVIA injection indicates that pain pathways were not activated. 




b

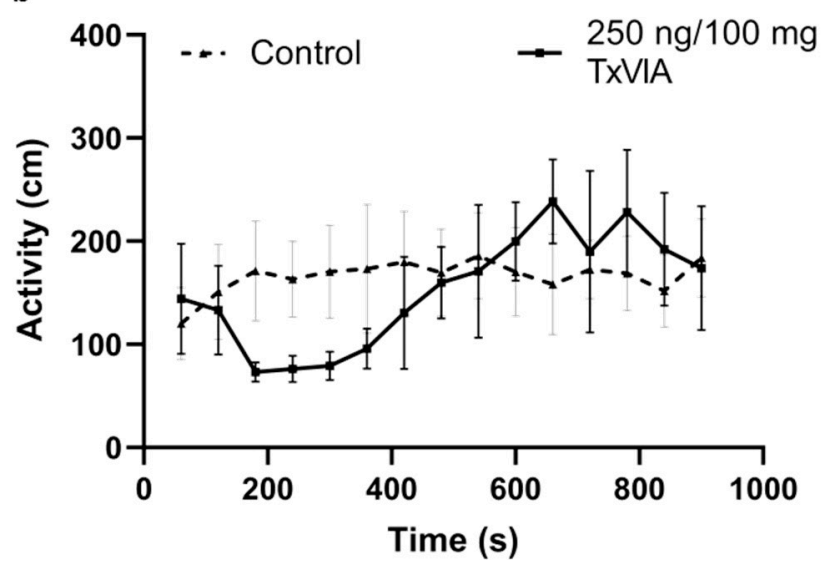

Figure 5. TxVIA-induced behavioural response in adult zebrafish $(n=3)$. (a) The six boxes illustrate the 15 min swimming tracks of the control zebrafish $(n=3)$ and the zebrafish injected with $250 \mathrm{ng} / 100 \mathrm{mg}$ fish of TxVIA $(n=3)$, respectively. The fish generally start with a comparatively slow swimming speed, indicated in black lines, and end with a regular swimming speed, indicated in green lines. Erratic or fast swimming tracks are indicated in red lines. (b) The adult zebrafish injected with $250 \mathrm{ng} / 100 \mathrm{mg}$ fish of TxVIA (continuous line) showed a reduced activity (measured by distance travelled per min) in the first $8 \mathrm{~min}$ compared to the activity of the control fish injected with saline sterilised water (dotted line), followed by a small burst of activities for $5 \mathrm{~min}$, and returned to normal gradually. Data are means \pm SEM.

\section{Discussion}

Conotoxins are potent and selective modulators of mammalian ion channels and receptors. The King Kong peptide TxVIA has previously been characterised as a mollusc $\mathrm{Na}_{\mathrm{V}}$ channel modulator, producing convulsive-like activity in snails [1] and paralytic effects in the mollusc Patella sp. [2]. In this study, we characterised the effects of TxVIA on human Navs and $\mathrm{Ca}_{V} 3 . x$, and zebrafish behaviours. These studies revealed for the first time that TxVIA is a nM inhibitor of Cav3.2 with activating activity on Cav3.1 at $\mu \mathrm{M}$ concentrations. Interestingly, high concentrations of TxVIA $(5 \mu \mathrm{M})$ were inactive on endogenously expressed $\mathrm{Na}_{V} s$ in SH-SY5Y cells, including $\mathrm{Na}_{V} 1.2$ and $\mathrm{Na}_{V} 1.7$, or heterologously expressed mouse $\mathrm{Na}_{\mathrm{V}} 1.7(10 \mu \mathrm{M})$. In addition, our experiments found that TxVIA does not trigger pain-like behaviours or paralysis in zebrafish at up to $250 \mathrm{ng} / 100 \mathrm{mg}$ fish, consistent with the lack of an excitatory effect on vertebrate $\mathrm{Na}_{V} \mathrm{~s}$. Although TxVIA did not target the $\mathrm{Ca}_{\mathrm{V}} 3 . \mathrm{x}$ window current like Cav3.x small molecule blockers [26,27], electrophysiological characterisation of TxVIA revealed it to be a nM inhibitor for $\mathrm{Ca}_{\mathrm{V}} 3.2\left(\mathrm{IC}_{50}=0.24 \mu \mathrm{M}\right)$. $\mathrm{Ca}_{\mathrm{V}} 3.2$ is considered to be a promising novel therapeutic target for pain with $\mathrm{Ca}_{\mathrm{V}} 3.2$ playing a major pronociceptive role in spinal nociceptive neurons and primary afferents [28-30].

Our LC-MS analysis of dissected C. textile venoms revealed that TxVIA was expressed at its highest levels in the central region of the venom duct as the dominant component. Previous studies from our laboratory have revealed that Conus geographus and Conus marmoreus have evolved to produce defensive and predatory venoms from the proximal and distal regions of the venom duct, respectively, that are deployed in response to the corresponding stimuli [31]. However, the role of central regions of the venom duct in these processes remains unknown. In future studies, we aim to investigate the contribution of TxVIA to the defensive and predatory milked venoms of $C$. textile to unravel its role in defensive and/or predatory behaviour.

To gain insight into TxVIA binding to $\mathrm{Na}_{\mathrm{V}}$ and $\mathrm{Ca}_{\mathrm{V}}$ channels, we performed molecular docking studies of TxVIA binding to Cryo-EM structures of $\mathrm{hNa}_{\mathrm{V}} 1.7$ and $\mathrm{hCa}$ 3.1. A strong salt bridge was identified in TxVIA binding to the DIV S1-S2 linker of Nav1.7, suggesting that the DIV S1-S2 linker could be a new binding site affecting $\mathrm{Na}_{\mathrm{V}}$ channel targeting neurotoxins. Our docking studies of TxVIA in hCav3.x showed that TxVIA binds to the DIV S3-S4 linker of Cav3.1 with a strong salt 
bridge, whereas it failed to dock to the DIV S3-S4 linker of $\mathrm{Ca}_{\mathrm{V}} 3.2$ and $\mathrm{Ca}_{\mathrm{V}} 3.3$. These results suggested that the interaction sites between TxVIA and $\mathrm{hCa}_{\mathrm{V}} 3 . x$ may differ among the three subtypes, which is supported by our electrophysiological data showing it has differential effects across the three subtypes. We speculate that the DIV S3-S4 linker may contribute to both the selective inhibition [25] and activation of the Cav3.1 current.

Toxins with the inhibitor cystine knot (ICK) motif have been mostly recognised as modulators of voltage-gated ion channels [32]. However, ICK peptides with related folds but different sequences often show altered selectivity for ion channels, indicative of promiscuous pharmacophore interactions. $\delta$-Conotoxin TxVIA has been reported to show a prominent hydrophobic patch covering one side of the peptide surface (Figure 6), which was proposed to be crucial for sodium channel binding [33], with our work confirming that TxVIA is non-functional at mammalian $\mathrm{Na}_{V}$ s. Interestingly, our docking results reveal that the side opposite to the prominent hydrophobic patch of TxVIA is involved in its binding to DIV extracellular loops of $\mathrm{Na}_{\mathrm{V}} 1.7$ (Figure 6), suggesting the hydrophobic patch in TxVIA only contributes to $\mathrm{Na}_{\mathrm{V}}$ channel affinity. Other $\mathrm{Ca}_{\mathrm{V}} 3 . x$ peptide blockers with selectivity for Cav3.2 include two hydrophobic tarantula toxins PsPTx3 [34,35] and ProTx-II [21] which also inhibits $\mathrm{Na}_{V}$ 1.7 [20]. Previous structure activity relationship (SAR) studies on ProTx-II reveal that hydrophobic patch interactions with membrane lipids are required for high affinity interactions with hNav1.7 [36] and $\mathrm{Na}_{V} 1.5$ [37]. Cav3.2 selective peptide blockers also typically show a prominent hydrophobic face, whereas non-hydrophobic peptide blocker ProTx-I inhibits Cav3.1 [21,25,38]. Indeed, our docking studies suggest that TxVIA also binds to the DIV S3-S4 linker of $\mathrm{Ca}_{V} 3.1$ through a more polar surface and not through the adjacent prominent hydrophobic patch (Figure 6).
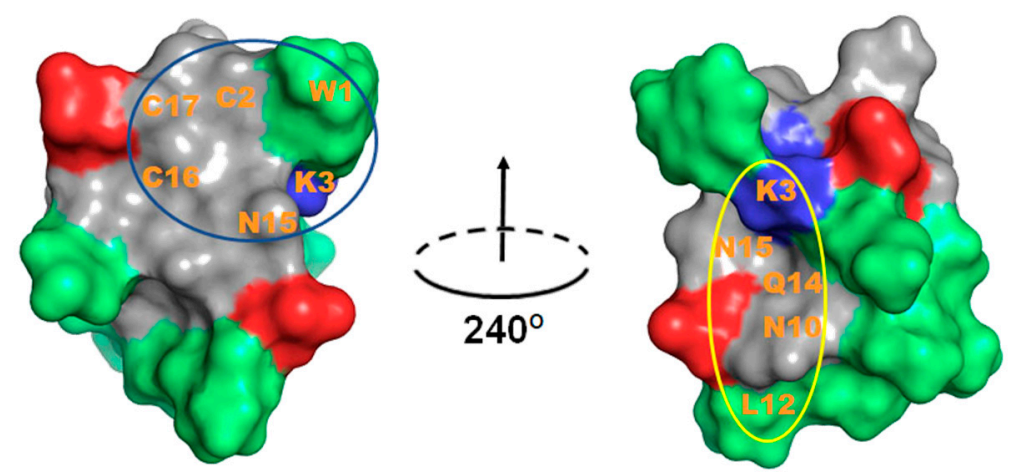

Figure 6. TxVIA (PDB 1FU3) structure pair obtained by $240^{\circ}$ horizontal rotation. Peptide surface presented with blue and red colours indicate positive and negative charged residues, respectively, and green colour indicates hydrophobic uncharged residues. The predicted buried surface of TxVIA binding to $\mathrm{Na}_{V} 1.7$ is circled in blue and the predicted buried surface of TxVIA binding to Cav3.1 is circled in yellow. The predicted interacting residues are labelled.

In conclusion, we have identified that $\delta$-conotoxin TxVIA modulates mammalian $\mathrm{Ca}_{\mathrm{V}} 3 . \mathrm{x}$, but not mammalian $\mathrm{Na}_{\mathrm{V}}$ channels. TxVIA represents a promising new tool to improve our understanding of the molecular mechanism and determinants of activation and inactivation of the different $\mathrm{Na}_{\mathrm{V}} 1 . x$ and Cav3.x subtypes.

\section{Materials and Methods}

All reagents were used as purchased from Sigma-Aldrich without further purification.

\subsection{LC/MS Analysis of TXVIA Distribution in the C. textile Venom Duct}

Thirteen adult C. textile specimens collected from One Tree Island on the Great Barrier Reef (Queensland, Australia) were sacrificed and dissected into four sections on ice. The crude venom was extracted into $30 \%$ acetonitrile, acidified with 0.1 formic acid. The collected 52 crude C. textile 
samples from each of the four duct sections $(5 \mu \mathrm{L})$ were chromatographically separated on an ultra HPLC system (Shimadzu Scientific, Rydalmere, Australia) directly coupled to a 5600 TripleTOF MS (SCIEX, Foster City, USA). The LC separation was achieved using a Zorbax $\mathrm{C}_{18} 4.6 \times 150 \mathrm{~mm}$ column at a linear $1.3 \% \mathrm{~B}$ (acetonitrile/0.1\% formic acid (aq)) $\mathrm{min}^{-1}$ gradient with a flow rate of $0.2 \mathrm{ml} \mathrm{min}^{-1}$ over $90 \mathrm{~min}$. Data were acquired over a time-of-flight (TOF) mass range of 350-2200 Da with an ion spray voltage of $5500 \mathrm{~V}$ (CUR 25, TEM 500, GS1 50 and GS2 60). Acquired data were then analysed with Sciex Analyst ${ }^{\mathrm{TF}} 1.6$ software.

\subsection{C. textile Crude Venom Fractionation for the Collection of Native TxVIA}

Solvent A consists of $0.05 \%$ trifluoroacetic acid (TFA) in milli-Q water, whereas solvent B consists of $0.043 \%$ TFA and $90 \%$ acetonitrile in water. $1.4 \mathrm{mg}$ of lyophilised C. textile crude venom dissolved in water with $30 \%$ solvent B was loaded using an UltiMate 3000 analytical autosampler (Dionex, Sunnyvale, CA) onto a 00G-4053-E0 Jupiter®(Phenomenex, Torrance, CA, USA) $5 \mu \mathrm{m} C 18300 \AA$, $250 \times 4.6 \mathrm{~mm}$ analytical reversed phase high performance liquid chromatography (RP-HPLC) column and eluted at a flow rate of $0.7 \mathrm{~mL} / \mathrm{min}$ over $100 \mathrm{~min}$. The elution was monitored at $214 \mathrm{~nm}$.

The following gradient generated by an UltiMate 3000 pump was used to fractionate the $C$. textile crude venom: A constant $5 \%$ solvent B over $5 \mathrm{~min}, 5-80 \%$ solvent B over $75 \mathrm{~min}, 80-90 \%$ solvent B over $1 \mathrm{~min}$, a constant $90 \%$ solvent B over $4 \mathrm{~min}, 90-5 \%$ solvent $B$ over $1 \mathrm{~min}$, and a constant $5 \%$ solvent $B$ over $1 \mathrm{~min}$.

A solvent blank run using the same gradient and equilibration with 5\% solvent B for $15 \mathrm{~min}$ preceded each separation. Fractions were collected every 1 min over $80 \mathrm{~min}$ with a Gilson FC 204 automatic fraction collector (Gilson, Middleton, WI). Collected fractions were transferred into 1.5 $\mathrm{mL}$ Eppendorf tubes, dried in a speed vacuum concentrator, resuspended in $100 \mu \mathrm{L}$ of milli-Q water, vortexed and stored at $-20^{\circ} \mathrm{C}$ prior to assaying. Peptide concentrations were measured using the NanoDrop One (Thermo Scientific, MA, US). All solvents used were HPLC grade.

\subsection{MS and MS/MS Analysis and Sequence Determination of Native TxVIA}

\subsubsection{MALDI-TOF Mass Spectrometry}

Venom peptide masses were verified by matrix-assisted laser desorption/ionisation time-of-flight mass spectrometry (MALDI-TOF MS) using the 4700 Proteomics Bioanalyzer (Applied Biosystems, CA, USA). Venom fractions in water obtained from RP-HPLC were mixed with the matrix CHCA $(5 \mathrm{mg} / \mathrm{mL}$ in $50 \% \mathrm{ACN}, 1 \% \mathrm{FA})$ in $1: 1(\mathrm{v} / \mathrm{v})$ ratio and spotted on a MALDI plate. MALDI-TOF spectra were collected in reflector positive mode and the reported masses are monoisotopic $\mathrm{M}+\mathrm{H}^{+}$ions.

\subsubsection{Reduction and Alkylation of Cysteine Residues}

$45 \mu \mathrm{L}$ peptide solution was reduced and alkylated with $50 \mu \mathrm{L}$ of reduction/alkylation cocktail (containing $97.5 \%$ acetonitrile, $2 \%$ iodoethanol, and $0.5 \%$ triethylphosphine by volume) in $50 \mathrm{mM}$ ammonium carbonate solution ( $\mathrm{pH} 11$ ), capped and incubated at $37^{\circ} \mathrm{C}$ for $2 \mathrm{~h}$. The sample was then uncapped and evaporated on a speed vacuum for more than $1 \mathrm{~h}$. Dried samples were kept in $-80^{\circ} \mathrm{C}$ before use.

\subsubsection{Trypsin Digestion}

Reduced and alkylated peptide was reconstituted with $20 \mu \mathrm{L}$ of $50 \mathrm{mM}$ ammonium bicarbonate solution ( $\mathrm{pH}$ 8). Peptide digestion was achieved in $40 \mathrm{ng} / \mu \mathrm{L}$ modified sequencing grade trypsin (Promega, Madison, WI, USA) incubated at $37^{\circ} \mathrm{C}$ overnight. Digestion was terminated by adding $5 \mu \mathrm{L}$ of $5 \%$ formic acid. 


\subsubsection{LC-MS/MS Analysis and Sequence Determination of Native TxVIA}

The tryptic peptides $(15 \mu \mathrm{L})$ were analysed with chromatographic separation using an ultra HPLC system (Shimadzu Scientific, Rydalmere, Australia) directly coupled to a 5600 TripleTOF MS (SCIEX, Foster City, USA). Data were acquired for $55 \mathrm{~min} 2 \mathrm{~s}$ with an ion spray voltage of $5500 \mathrm{~V}$ (CUR 25, TEM 500, GS1 50 and GS2 60). ProteinPilot ${ }^{\mathrm{TM}} 4.0$ software (SCIEX) with the Paragon Algorithm was used for protein identification. Tandem mass spectrometry (MS/MS) data was searched against database of $C$. textile from conoserver (http://conoserver.org/). The search parameters were defined as iodoethanol modified for cysteine alkylation and trypsin as the digestion enzyme.

\subsection{Cell Culture and Transient Expression}

The human embryonic kidney 293 (HEK293) cell line expressing human Cav3.2 or Cav3.3 (kind gift from Emmanuel Bourinet, University of Montpellier, France) were cultured under 5\% carbon dioxide at $37^{\circ} \mathrm{C}$ in Dulbecco's modified Eagle's medium (DMEM), Glutamax (Gibco, Life Technologies, Carlsbad, CA, US) supplemented with $10 \%$ (v/v) fetal bovine serum (FBS), $100 \mathrm{U} / \mathrm{mL}$ penicillin, $100 \mu \mathrm{g} / \mathrm{mL}$ streptomycin (Gibco, Life Technologies) and $750 \mu \mathrm{g} / \mathrm{mL}$ geneticin (G418) (Gibco, Life Technologies). The Chinese hamster ovary (CHO) cell lines (Emmanuel Bourinet, Montpellier, France) expressing human $\mathrm{Ca}_{\mathrm{V}} 3.1$ were cultured under $5 \%$ carbon dioxide at $37{ }^{\circ} \mathrm{C}$ in Minimum Essential Medium Eagle-alpha modification ( $\alpha$-MEM) Glutamax (Gibco, Life Technologies), supplemented with $10 \%$ (v/v) FBS and $300 \mu \mathrm{g} / \mathrm{mL}$ geneticin (G418) (Gibco, Life Technologies). The human neuroblastoma SH-SY5Y cells (Victor Diaz, Goettingen, Germany) were cultured under $5 \%$ carbon dioxide at $37^{\circ} \mathrm{C}$ in RPMI 1640 antibiotic-free medium (Invitrogen, Carlsbad, CA, US), supplemented with 15\% FBS and $2 \mathrm{mM}$ GlutaMAX ${ }^{\mathrm{TM}}$ (Invitrogen). Dulbecco's phosphate-buffered saline (DPBS) (Gibco, Life Technologies) was used to wash the cells, and $0.25 \%$ Trypsin-EDTA (Gibco, Life Technologies) was used to detach cells from the flask surface. They were split in a ratio of $1: 5$ (ideally $10,000 \mathrm{cells} / \mathrm{cm}^{2}$ ) when they reached $70-80 \%$ confluency (every $2-3$ days). Transiently transfected $\mathrm{Na}_{V} 1.7$ HEK293T cells were used in the sodium channel FLIPR assay. HEK293T cells were cultured under $5 \%$ carbon dioxide at $37^{\circ} \mathrm{C}$ in DMEM Glutamax supplemented with $10 \%$ (v/v) FBS. DPBS was used to wash the cells, and $0.25 \%$ Trypsin-EDTA was used to detach cells from the flask surface. The cells were split and seeded at 3 million cells per T75 flask, to reach $70-80 \%$ confluency after $24 \mathrm{~h}$. The next day, $10 \mu \mathrm{g}$ plasmid DNA of mouse $\mathrm{Na}_{V} 1.7 \alpha$ subunit (GenScript, Piscataway, USA) was incubated in $500 \mu \mathrm{L}$ serum-free DMEM Glutamax with $30 \mu \mathrm{L}$ FuGENE HD transfection reagent (Promega Corporation, Madison, WI, USA) (1:3 DNA/Fugene ratio) for $20 \mathrm{~min}$, and then the mixture was added into the cell flask slowly, drop by drop. After the transfection, the cells were cultured under $5 \%$ carbon dioxide at $37^{\circ} \mathrm{C}$ for $16 \mathrm{~h}$ and then moved to a $28^{\circ} \mathrm{C}$ incubator prior to use.

\subsection{Sodium Channel FLIPR Assay}

SH-SY5Y cells or transiently transfected Nav1.7 HEK293T cells were seeded into 384-well black wall clear bottom plates at a density of 15,000 cells or 30,000 cells per well, respectively, resulting in $90-95 \%$ confluency after $24 \mathrm{~h}$. The media were then removed from the wells and replaced with $20 \mu \mathrm{L}$ of $10 \%$ red membrane potential dye (Molecular Devices, Sunnyvale, CA) in physiological salt solution (PSS) containing $5.9 \mathrm{mM} \mathrm{KCl}, 1.4 \mathrm{mM} \mathrm{MgCl}, 10 \mathrm{mM}$ HEPES, $1.2 \mathrm{mM} \mathrm{NaH} \mathrm{PO}_{4}, 5 \mathrm{mM} \mathrm{NaHCO}_{3}$, $140 \mathrm{mM} \mathrm{NaCl}, 11.5 \mathrm{mM}$ glucose, $1.8 \mathrm{mM} \mathrm{CaCl}_{2}$ and $0.1 \%$ BSA at $\mathrm{pH}$ 7.4. The cells were incubated for $30 \mathrm{~min}$ at $37^{\circ} \mathrm{C}$ in the presence of $5 \%$ carbon dioxide. The plates were placed in the FLIPR ${ }^{\text {TETRA }}$ (Molecular Devices, Sunnyvale, CA, USA) programmed to record the fluorescence responses under baseline fluorescence 1500-2000 arbitrary fluorescence units (AFU), emission wavelength 565-625 nm, and excitation wavelength $510-545 \mathrm{~nm}$. Prior to the addition of PSS $(0.1 \% \mathrm{BSA})$ with or without peptide or $10 \mu \mathrm{M} / 1 \mu \mathrm{M}$ TTX, five baseline fluorescence readings were recorded. The fluorescence readings were then recorded once every two seconds over a period of $600 \mathrm{~s}$, resulting in a total of 305 reads before the agonist was added. One fluorescence reading was taken before the second addition. 
After PSS (0.1\% BSA) for negative control or agonist containing $40-50 \mu \mathrm{M}$ veratridine was loaded, the fluorescence readings were recorded every two seconds for $600 \mathrm{~s}$, resulting in a total 301 reads. $n$ independent experiments were conducted in triplicates. Raw fluorescence readings in the form of relative light units were converted to response over baseline using ScreenWorks $₫($ Molecular Devices, version 3.2.0.14) software.

\subsection{T-type Calcium Channel Window Current FLIPR Assays}

HEK293 cells stably expressing Cav3 3 .2 were seeded into 384-well black wall clear bottom plates (Corning, Lowell, MA, US) at a density of 30,000 cells per well. Once the cells reached $80-90 \%$ confluency after $24 \mathrm{~h}$, the media were removed from the wells and replaced with $20 \mu \mathrm{L}$ of $10 \%$ calcium 4 dye (Molecular Devices, Sunnyvale, CA, USA) in Hank's balanced salt solution-HEPES (HBSS-HEPES) (containing $5 \mathrm{mM} \mathrm{KCl}, 10 \mathrm{mM}$ HEPES, $140 \mathrm{mM} \mathrm{NaCl}, 10 \mathrm{mM}$ glucose and $0.5 \mathrm{mM} \mathrm{CaCl}_{2}, \mathrm{pH} 7.4$ ) with $0.1 \%$ bovine serum albumin (BSA). The cells were incubated for $30 \mathrm{~min}$ at $37^{\circ} \mathrm{C}$ in the presence of $5 \%$ carbon dioxide. The plates were placed in the FLIPR ${ }^{\text {TETRA }}$ programmed to measure maximum fluorescence intensity following a second addition of the agonist $5 \mathrm{mM} \mathrm{CaCl}_{2}$. The data acquisition parameters were adjusted as follows: baseline fluorescence 1500-2000 AFU, emission wavelength 515-575 nm, excitation wavelength 470-495 nm. Prior to the addition of HBSS-HEPES (0.1\% BSA) with or without peptide, five baseline fluorescence readings were recorded. The fluorescence readings were then recorded once every two seconds over a period of $600 \mathrm{~s}$, resulting in a total of 305 reads before the agonist was added. One fluorescence reading was taken before the second addition. After $\mathrm{CaCl}_{2}$ was loaded, the fluorescence readings were recorded every second for $300 \mathrm{~s}$, resulting in a total 301 reads. Raw fluorescence readings in the form of relative light units were converted to response over baseline using ScreenWorks@(Molecular Devices, version 3.2.0.14) software [15].

\subsection{Whole-Cell Patch-Clamp Electrophysiology}

Whole-cell patch-clamp experiments were performed on an automated electrophysiology platform QPatch 16X (Sophion Bioscience A/S, Ballerup, Denmark) in single-hole configuration using 16-channel planar patch chip QPlates (Sophion Bioscience A/S). The extracellular recording solution contained: $157 \mathrm{mM}$ TEACl, $0.5 \mathrm{mM} \mathrm{MgCl} 2,5 \mathrm{mM} \mathrm{CaCl}_{2}$ and $10 \mathrm{mM}$ HEPES; pH 7.4 adjusted with TEAOH; and osmolarity $320 \mathrm{mOsm}$. The intracellular pipette solution contained: $140 \mathrm{mM}$ CsF, $1 \mathrm{mM}$ EGTA, $10 \mathrm{mM}$ HEPES and $10 \mathrm{mM} \mathrm{NaCl}$; $\mathrm{pH} 7.2$ adjusted with $\mathrm{CsOH}$; and osmolarity 325 mOsm. TxVIA was diluted in extracellular recording solution with $0.1 \%$ BSA at the concentrations stated, and the TxVIA effects were compared to the control (extracellular solution with $0.1 \%$ BSA) parameters within the same cell. TxVIA incubation time varied from two (for the highest concentration) to five (for the lowest concentration) minutes by applying the voltage protocol 10-30 times at $10 \mathrm{~s}$ intervals to ensure steady-state inhibition was achieved. The effects of TxVIA were obtained using $200 \mathrm{~ms}$ voltage steps to peak potential from a holding potential of $-90 \mathrm{mV}$. Current-voltage $(I-V)$ relationships were obtained by holding the cells at a potential of $-100 \mathrm{mV}$ before applying $50 \mathrm{~ms}$ pulses to potentials from -75 to $+50 \mathrm{mV}$ every $5 \mathrm{~s}$ in $5 \mathrm{mV}$ increments. Data were fitted with a single Boltzmann distribution: $I / I_{\max }=\left(1+\exp \left(V-V_{50}\right) / k\right)^{-1}$, where $V_{50}$ is the half-availability voltage and $k$ is the slope factor. A single-voltage protocol was applied in between to measure the TxVIA effect. One cell was considered as an independent experiment. Off-line data analysis was performed using QPatch Assay Software v5.6 (Sophion Bioscience A/S) and Excel 2013 (Microsoft Corporation, Redmond, WA, USA).

\subsection{Homology Modeling and Molecular Docking}

Homology models of human Cav3.2 and Cav3.3 were generated by SWISS-MODEL [39] using human Cav3.1 Cryo-EM structure [24] as template. FASTA sequences for human Cav3.2 and Cav3.3 were obtained from UniProt and used as query sequences. The resulting models were energy minimised using the GROMOS force field, validated by Ramachandran plot analysis, visualised in PyMol and used for molecular docking using Autodock Vina [40]. For molecular docking of TxVIA in human Na 1.7 , 
we used the DIV S3-S4 linker of previously published human $\mathrm{Na}_{\mathrm{V}} 1.7-\beta 1-\beta 2$ Cryo-EM structure (PDB 6J8I) [19], as well as the DII S3-S4 linker (missing in the structure of 6J8I) of human $\mathrm{Na}_{\mathrm{V}} 1.7$ Cryo-EM structure (PDB 6N4I) [23]. To define the search space for the DIV S3-S4 linker of the hNa 1.7 structure, a grid box with the following dimensions: center $x=96.256$, center $y=136.521$, center $z=155.042$ was used. To define the search space for the DII S3-S4 linker of hNav1.7 structure, a grid box with the following dimensions: center $x=82.85$, center $y=288.228$, center $z=213.878$, was used. The size of the grid box for all the docking in hNav1.7 was as follows: size $x=30$, size $y=30$, size $z=30$. For molecular docking of $\mathrm{hCa}_{\mathrm{V}} 3.1, \mathrm{hCa}$ 3.2, hCav 3.3 DIV S3-S4 linker with TxVIA, a grid box with the following dimensions: center $x=166.339$, center $y=123.395$, center $z=199.419$ was used. The size of the grid box for all the docking in $\mathrm{hCa}_{\mathrm{V}} 3$.x was as follows: size $x=25$, size $y=25$, size $z=25$. The exhaustiveness for the search was set to 8 .

\subsection{Evaluation of Zebrafish Pain Behaviours after Intramuscular Injection of TxVIA}

Zebrafish were maintained using standard husbandry procedures, conforming to ethical guidelines of the animal ethics committees at the University of Queensland. Six-month old male zebrafish with similar body size and weight were prepared for the assay. Samples were tested via intramuscular injections $(5 \mu \mathrm{L})$ using a Hamilton syringe (Sigma-Aldrich no. 20795-U). Different concentrations of TxVIA were injected intramuscularly, and the same volume of saline sterilised water was used as control. Three fish were injected per condition. Injected animals were placed in $500 \mathrm{~mL}$ containers and their swimming tracks/behaviours were recorded using a custom Zebrabox revolution (Viewpoint) imaging platform and as previously described [41,42]. The animals were observed using the automatic imaging platform for $15 \mathrm{~min}$ in dark condition followed by manual monitoring in laboratory light conditions at $28^{\circ} \mathrm{C}$ for up to $24 \mathrm{~h}$ post-injections. Bursts of erratic swimming were recorded as an indicator of pain behaviours as previously described [14,43].

\subsection{Data Analysis}

Data were plotted and analysed using GraphPad Prism v8.2.1 (GraphPad Software Inc., San Diego, CA, USA). A four-parameter logistic Hill equation with variable Hill coefficients was fitted to the data for concentration-response curves. Data are means \pm SEM of $n$ independent experiments. Statistical analysis was performed with a paired Student's $t$-test with statistical significance at $p<0.05$.

Author Contributions: Conceptualisation, R.J.L.; methodology, D.W., S.W.A.H., J.G., M.M.H. and L.R.; validation, D.W., S.W.A.H., J.G., M.M.H., F.C.C., L.R. and R.J.L.; formal analysis, D.W., M.M.H., S.W.A.H. and J.G.; sample preparation, D.W. and S.W.A.H.; calcium channel activity investigation, D.W.; sodium channel activity investigation, D.W. and M.M.H.; homology modeling and molecular docking, M.M.H. and D.W.; zebrafish behavioural investigation, D.W. and J.G.; data Curation, D.W.; writing-original draft preparation, D.W.; writing-review and editing, D.W., S.W.A.H., J.G., M.M.H., F.C.C., L.R. and R.J.L.; supervision, L.R. and R.J.L.; funding acquisition, R.J.L. All authors have read and agreed to the published version of the manuscript.

Funding: This research was supported by NHMRC Program Grant number APP1072113 and an NHMRC Principal Research Fellowship (to RJL). The zebrafish component has also been supported by a NHMRC Investigator Grant APP1174145 and a Rebecca L. Cooper Medical research Project Grant PG2019405 (to JG).

Acknowledgments: The authors thank Emmanuel Bourinet for donating stable cell lines for T-type calcium channels, Alun Jones for helping with mass spectrometric analysis and all the Lewis group members who have contributed to the $C$. textile maintenance and venom collection.

Conflicts of Interest: The authors declare no conflict of interest.

\section{References}

1. Hillyard, D.R.; Olivera, B.M.; Woodward, S.; Corpuz, G.P.; Gray, W.R.; Ramilo, C.A.; Cruz, L.J. A molluskivorous Conus toxin: Conserved frameworks in conotoxins. Biochemistry 1989, 28, 358-361. [CrossRef]

2. Fainzilber, M.; Gordon, D.; Hasson, A.; Spira, M.E.; Zlotkin, E. Mollusc-specific toxins from the venom of Conus textile neovicarius. Eur. J. Biochem. 1991, 202, 589-595. [CrossRef] 
3. Hasson, A.; Fainzilber, M.; Gordon, D.; Zlotkin, E.; Spira, M.E. Alteration of sodium currents by new peptide toxins from the venom of a molluscivorous Conus snail. Eur. J. Neurosci. 1993, 5, 56-64. [CrossRef] [PubMed]

4. Fainzilber, M.; Kofman, O.; Zlotkin, E.; Gordon, D. A new neurotoxin receptor site on sodium channels is identified by a conotoxin that affects sodium channel inactivation in molluscs and acts as an antagonist in rat brain. J. Biol. Chem. 1994, 269, 2574-2580. [PubMed]

5. Gonoi, T.; Ashida, K.; Feller, D.; Schmidt, J.; Fujiwara, M.; Catterall, W.A. Mechanism of action of a polypeptide neurotoxin from the coral Goniopora on sodium channels in mouse neuroblastoma cells. Mol. Pharmacol. 1986, 29, 347. [PubMed]

6. Gonoi, T.; Ohizumi, Y.; Kobayashi, J.; Nakamura, H.; Catterall, W.A. Actions of a polypeptide toxin from the marine snail Conus striatus on voltage-sensitive sodium channels. Mol. Pharmacol. 1987, 32, 691-698.

7. Kostyuk, P.; Mironov, S.; Shuba, Y.M. Two ion-selecting filters in the calcium channel of the somatic membrane of mollusc neurons. J. Membr. Biol. 1983, 76, 83-93. [CrossRef]

8. Spafford, J.D.; Spencer, A.N.; Gallin, W.J. Genomic organization of a voltage-gated $\mathrm{Na}^{+}$channel in a hydrozoan jellyfish: Insights into the evolution of voltage-gated $\mathrm{Na}^{+}$channel genes. Recept. Channels 1999, 6, 493-506.

9. Gray, L.S.; Macdonald, T.L. The pharmacology and regulation of T type calcium channels: New opportunities for unique therapeutics for cancer. Cell Calcium 2006, 40, 115-120. [CrossRef]

10. Rossier, M.F. T-type calcium channel: A privileged gate for calcium entry and control of adrenal steroidogenesis. Front. Endocrinol. 2016, 7, 43. [CrossRef] [PubMed]

11. Wang, D.; Ragnarsson, L.; Lewis, R.J. T-type calcium channels in health and disease. Curr. Med. Chem. 2020, 27, 3098-3122. [CrossRef]

12. Vetter, I.; Mozar, C.A.; Durek, T.; Wingerd, J.S.; Alewood, P.F.; Christie, M.J.; Lewis, R.J. Characterisation of $\mathrm{Na}_{\mathrm{V}}$ types endogenously expressed in human SH-SY5Y neuroblastoma cells. Biochem. Pharmacol. 2012, 83, 1562-1571. [CrossRef] [PubMed]

13. Khan, K.M.; Collier, A.D.; Meshalkina, D.A.; Kysil, E.V.; Khatsko, S.L.; Kolesnikova, T.; Morzherin, Y.Y.; Warnick, J.E.; Kalueff, A.V.; Echevarria, D.J. Zebrafish models in neuropsychopharmacology and CNS drug discovery. Br. J. Pharmacol. 2017, 174, 1925-1944. [CrossRef] [PubMed]

14. Speedie, N.; Gerlai, R. Alarm substance induced behavioral responses in zebrafish (Danio rerio). Behav. Brain Res. 2008, 188, 168-177. [CrossRef] [PubMed]

15. Wang, D.; Neupane, P.; Ragnarsson, L.; Capon, R.J.; Lewis, R.J. Synthesis of pseudellone analogs and characterization as novel T-type calcium channel blockers. Mar. Drugs 2018, 16, 475. [CrossRef]

16. Thomsen, W.J.; Catterall, W.A. Localization of the receptor site for $\alpha$-scorpion toxins by antibody mapping: Implications for sodium channel topology. Proc. Natl. Acad. Sci. USA 1989, 86, 10161-10165. [CrossRef]

17. Rogers, J.C.; Qu, Y.; Tanada, T.N.; Scheuer, T.; Catterall, W.A. Molecular determinants of high affinity binding of $\alpha$-scorpion toxin and sea anemone toxin in the S3-S4 extracellular loop in domain IV of the $\mathrm{Na}^{+}$channel $\alpha$ subunit. J. Biol. Chem. 1996, 271, 15950-15962. [CrossRef]

18. Clairfeuille, T.; Cloake, A.; Infield, D.T.; Llongueras, J.P.; Arthur, C.P.; Li, Z.R.; Jian, Y.; Martin-Eauclaire, M.-F.; Bougis, P.E.; Ciferri, C. Structural basis of $\alpha$-scorpion toxin action on $\mathrm{Na}_{\mathrm{V}}$ channels. Science 2019, 363, eaav8573. [CrossRef]

19. Shen, H.; Liu, D.; Wu, K.; Lei, J.; Yan, N. Structures of human Nav1.7 channel in complex with auxiliary subunits and animal toxins. Science 2019, 363, 1303-1308. [CrossRef]

20. Schmalhofer, W.A.; Calhoun, J.; Burrows, R.; Bailey, T.; Kohler, M.G.; Weinglass, A.B.; Kaczorowski, G.J.; Garcia, M.L.; Koltzenburg, M.; Priest, B.T. ProTx-II, a selective inhibitor of Na 1.7 sodium channels, blocks action potential propagation in nociceptors. Mol. Pharmacol. 2008, 74, 1476-1484. [CrossRef]

21. Bladen, C.; Hamid, J.; Souza, I.A.; Zamponi, G.W. Block of T-type calcium channels by protoxins I and II. Mol. Brain 2014, 7, 36. [CrossRef] [PubMed]

22. Stevens, M.; Peigneur, S.; Tytgat, J. Neurotoxins and their binding areas on voltage-gated sodium channels. Front Pharmacol. 2011, 2, 71. [CrossRef] [PubMed]

23. Xu, H.; Li, T.; Rohou, A.; Arthur, C.P.; Tzakoniati, F.; Wong, E.; Estevez, A.; Kugel, C.; Franke, Y.; Chen, J.; et al. Structural basis of $\mathrm{Na}_{\mathrm{V}} 1.7$ inhibition by a gating-modifier spider toxin. Cell 2019, 176, 702-715. [CrossRef]

24. Zhao, Y.; Huang, G.; Wu, Q.; Wu, K.; Li, R.; Lei, J.; Pan, X.; Yan, N. Cryo-EM structures of apo and antagonist-bound human Cav3.1. Nature 2019, 576, 492-497. [CrossRef] [PubMed] 
25. Ohkubo, T.; Yamazaki, J.; Kitamura, K. Tarantula toxin ProTx-I differentiates between human T-type voltage-gated $\mathrm{Ca}^{2+}$ Channels Cav3.1 and Cav3.2. J. Pharmacol. Sci. 2010, 112, 452-458. [CrossRef] [PubMed]

26. Uebele, V.N.; Nuss, C.E.; Fox, S.V.; Garson, S.L.; Cristescu, R.; Doran, S.M.; Kraus, R.L.; Santarelli, V.P.; Li, Y.; Barrow, J.C. Positive allosteric interaction of structurally diverse T-type calcium channel antagonists. Cell Biochem. Biophys. 2009, 55, 81-93. [CrossRef] [PubMed]

27. Tringham, E.; Powell, K.L.; Cain, S.M.; Kuplast, K.; Mezeyova, J.; Weerapura, M.; Eduljee, C.; Jiang, X.; Smith, P.; Morrison, J.-L. T-type calcium channel blockers that attenuate thalamic burst firing and suppress absence seizures. Sci. Transl. Med. 2012, 4, 121ra19. [CrossRef]

28. Bourinet, E.; Alloui, A.; Monteil, A.; Barrere, C.; Couette, B.; Poirot, O.; Pages, A.; McRory, J.; Snutch, T.P.; Eschalier, A. Silencing of the Cav3.2 T-type calcium channel gene in sensory neurons demonstrates its major role in nociception. EMBO J. 2005, 24, 315-324. [CrossRef]

29. Maeda, Y.; Aoki, Y.; Sekiguchi, F.; Matsunami, M.; Takahashi, T.; Nishikawa, H.; Kawabata, A. Hyperalgesia induced by spinal and peripheral hydrogen sulfide: Evidence for involvement of Cav3.2 T-type calcium channels. Pain 2009, 142, 127-132. [CrossRef]

30. Choi, S.; Na, H.; Kim, J.; Lee, J.; Lee, S.; Kim, D.; Park, J.; Chen, C.C.; Campbell, K.; Shin, H.S. Attenuated pain responses in mice lacking Cav3.2 T-type channels. Genes Brain Behav. 2007, 6, 425-431. [CrossRef]

31. Dutertre, S.; Jin, A.-H.; Vetter, I.; Hamilton, B.; Sunagar, K.; Lavergne, V.; Dutertre, V.; Fry, B.G.; Antunes, A.; Venter, D.J. Evolution of separate predation-and defence-evoked venoms in carnivorous cone snails. Nat. Commun. 2014, 5, 3521. [CrossRef] [PubMed]

32. Craik, D.J.; Daly, N.L.; Waine, C. The cystine knot motif in toxins and implications for drug design. Toxicon 2001, 39, 43-60. [CrossRef]

33. Kohno, T.; Sasaki, T.; Kobayashi, K.; Fainzilber, M.; Sato, K. Three-dimensional solution structure of the sodium channel agonist/antagonist $\delta$-conotoxin TxVIA. J. Biol. Chem. 2002, 277, 36387-36391. [CrossRef]

34. Bourinet, E.; Escoubas, P.; Marger, F.; Nargeot, J.; Lazdunski, M. Identification of novel antagonist toxins of T-Type calcium channel for analgesic purposes. U.S. Patent 8,664,179, 4 March 2014.

35. Bourinet, E.; Zamponi, G.W. Block of voltage-gated calcium channels by peptide toxins. Neuropharmacology 2017, 127, 109-115. [CrossRef] [PubMed]

36. Henriques, S.T.; Deplazes, E.; Lawrence, N.; Cheneval, O.; Chaousis, S.; Inserra, M.; Thongyoo, P.; King, G.F.; Mark, A.E.; Vetter, I. Interaction of tarantula venom peptide ProTx-II with lipid membranes is a prerequisite for its inhibition of human voltage-gated sodium channel $\mathrm{Na}_{\mathrm{V}}$ 1.7. J. Biol. Chem. 2016, 291, 17049-17065. [CrossRef] [PubMed]

37. Smith, J.J.; Cummins, T.R.; Alphy, S.; Blumenthal, K.M. Molecular interactions of the gating modifier toxin, ProTx-II, with $\mathrm{Na}_{\mathrm{V}}$ 1.5: Implied existence of a novel toxin binding site coupled to activation. J. Biol. Chem. 2007, 282, 12687-12697. [CrossRef]

38. Priest, B.T.; Blumenthal, K.M.; Smith, J.J.; Warren, V.A.; Smith, M.M. ProTx-I and ProTx-II: Gating modifiers of voltage-gated sodium channels. Toxicon 2007, 49, 194-201. [CrossRef]

39. Waterhouse, A.; Bertoni, M.; Bienert, S.; Studer, G.; Tauriello, G.; Gumienny, R.; Heer, F.T.; de Beer, T.A.P.; Rempfer, C.; Bordoli, L.; et al. SWISS-MODEL: Homology modelling of protein structures and complexes. Nucleic Acids Res. 2018, 46, W296-W303. [CrossRef]

40. Trott, O.; Olson, A.J. AutoDock Vina: Improving the speed and accuracy of docking with a new scoring function, efficient optimization, and multithreading. J. Comput. Chem. 2010, 31, 455-461. [CrossRef]

41. Giacomotto, J.; Rinkwitz, S.; Becker, T.S. Effective heritable gene knockdown in zebrafish using synthetic microRNAs. Nat. Commun. 2015, 6, 1-11. [CrossRef]

42. Laird, A.S.; Mackovski, N.; Rinkwitz, S.; Becker, T.S.; Giacomotto, J. Tissue-specific models of spinal muscular atrophy confirm a critical role of SMN in motor neurons from embryonic to adult stages. Hum. Mol. Genet. 2016, 25, 1728-1738. [CrossRef] [PubMed]

43. Himaya, S.W.A.; Jin, A.-H.; Dutertre, S.; Giacomotto, J.; Mohialdeen, H.; Vetter, I.; Alewood, P.F.; Lewis, R.J. Comparative venomics reveals the complex prey capture strategy of the piscivorous cone snail Conus catus. J. Proteome Res 2015, 14, 4372-4381. [CrossRef] [PubMed]

(C) 2020 by the authors. Licensee MDPI, Basel, Switzerland. This article is an open access article distributed under the terms and conditions of the Creative Commons Attribution (CC BY) license (http://creativecommons.org/licenses/by/4.0/). 